\title{
NATŪRALIŲ GAMTINIŲ GYDOMŲJŲ VEIKSNIŲ POVEIKIS PSICHOEMOCINEI IR FIZINEI DARBINGO AMŽIAUS ŽMONIŲ SVEIKATAI
}

\author{
Ugnẻ Žilinskaitė ${ }^{1}$, Lina Varžaitytè ${ }^{2}$ \\ ${ }^{1}$ Respublikiné Kauno ligonine, ${ }^{2}$ Lietuvos sveikatos mokslu universitetas, Reabilitacijos klinika
}

\begin{abstract}
Raktažodžiai: natūralioji aplinka, balneoterapija, fizinè ir psichikos sveikata, stresas ir natūrali gamta, klimatas ir sveikata.
\end{abstract}

\begin{abstract}
Santrauka
Žmogaus sveikata, jo psichikos būklè glaudžiai siejasi su natūraliai mus supančia gamta bei jos ištekliais. Pasaulyje gydymo tikslais naudojami ịvairūs gamtos ištekliai. Ypatinga reikšmè skiriama ịprastiniam kasdieniam buvimui ir fizinei veiklai gamtoje, sukantis natūraliam sveikatos ratui - gamtoje gerēja psichikos sveikata, o kartu ir fizinè asmens būklè, arba atvirkščiai.

Tyrimo tikslas - įvertinti natūralių gamtinių gydomujų veiksnių: natūraliosios aplinkos ir mineralinio vandens poveikị žmogaus fizinei bei psichikos sveikatai.

Sisteminė mokslinès literatūros paieška atlikta tarptautinèse PubMed ir Google Scholar duomenų bazèse. Atrinkti 44 ne senesni nei 10 metų straipsniai, kuriuose aprašyti natūralių gamtinių gydomujų veiksnių įtaką sveikatai nagrinèjantys tyrimai, aprépiantys duomenis apie šių veiksnių teigiamą poveikị žmogaus fizinei ir psichikos sveikatai. Atlikta straipsnių apžvalga ir turinio analizè.

Rezultatai ir išvados patvirtino faktą, kad gamta ir žmogus - dvi neatsiejamos materijos. Daugelị ligų galima gydyti vien natūraliais gamtos ištekliais, kartu pagerinant ir sustiprinant žmogaus psichikos būklę bei siekiant visapusio organizmo komforto.
\end{abstract}

\section{Ivadas}

Dabartiniais inovatyviais ir vis greitejančio gyvenimo tempo laikais kiekvienas iš mūsų buityje ar (ir) darbe patiriame įvairaus pobūdžio stresą. Yra duomenų, kad kasdienis stresas, veikdamas fizinę ir psichoemocinę sveikatą, sukelia nemažai ligų [1]. Daugeliu atvejų tai ne vien psichikos būklę veikiantys susirgimai. Streso poveikis siejamas su širdies ir kraujagyslių sistemos, virškinamojo trakto, endokrininès sistemos ligomis. Stresas paspartina uždegiminių procesų organizme atsiradimą [2,3]. Ypač daugèja reumatinių ligų, tokiu kaip reumatoidinis artritas (nuo 0,3 iki 1 proc. visos populiacijos), osteoartritas (15 proc. visos populiacijos), kurios pasireiškia vis jaunesniame amžiuje, t.y. iki 65 metu $[4,5]$. Neretai vienam asmeniui nustatoma keletas lètinių ligų, kurios tiesiogiai blogina ir psichikos sveikatą. Susidaro nenutrūkstamas ratas - fizinè sveikata daro poveikị asmens psichikos sveikatai ir atvirkščiai [6-11]. Tokiu atveju pasiekti visokeriopos asmens gerovès vien medikamentiniu gydymu neịmanoma, todèl vis dažniau ị gydymo procesą įtraukiama balneoterapija, peloidoterapija ir atsižvelgiama ị klimato veiksnius, turinčius teigiamos įtakos ịvairių susirgimų gydymui $[12,13]$.

Tyrimo tikslas - įvertinti natūralių gamtinių gydomujų veiksnių: natūraliosios aplinkos ir mineralinio vandens poveiki žmogaus fizinei bei psichikos sveikatai.

\section{Tyrimo medžiaga ir metodai}

Literatūros paieška atlikta 2020 m. sausio mèn., naudojant PubMed bei Google Scholar duomenų bazių paieškos sistemas. Straipsnių tinkamumo kriterijai: ne senesni nei 10 metų; aprašomi tyrimai, nagrinèjantys natūralių gamtinių veiksnių įtaką žmogaus sveikatai. Atmesti daugiau nei prieš 10 metų parašyti straipsniai, taip pat tokie, kuriuose nepatvirtintas faktas, jog natūralūs gamtiniai veiksniai ir žmogaus sveikata yra susiję. Atlikta straipsnių sisteminè apžvalga ir aprašomoji turinio analize, išanalizuotos tyrimo metu taikytos metodikos, rezultatų patikimumas.

\section{Rezultatai ir jų aptarimas}

Tinkamais pripažinti ir išanalizuoti 44 moksliniai straipsniai, kuriuose pateikiami duomenys apie natūralių gamtinių gydomujų veiksnių teigiamą poveiki žmogaus fizinei ir psichikos sveikatai. 
Buvimo gamtoje ịtaka žmogaus psichikos ir fizinei sveikatai. Yra duomenų, kad buvimas natūralioje gamtoje gali ne tik pagerinti žmogaus nuotaiką, tačiau ir sumažinti nuovargi. Šiuolaikinè urbanizacija, manoma, neigiamai veikia žmogaus psichikos sveikatą ir pažintines funkcijas, o tai asmenims, ypač darbingo amžiaus, sukelia protinį nuovargị $[14,15]$.

Sodininkystè, daržininkystė ar paprasčiausias gamtos stebẻjimas gali gerokai pagerinti psichologinę žmogaus būklę, tureti teigiamos įtakos širdies ir kraujagyslių bei kvèpavimo sistemos ligų gydymui. Pvz., Australijoje atliktų tyrimų metu pastebėta, kad asmenų, gyvenančių gausiose žalumos gyvenvietėse, sergamumas širdies ir kraujagyslių ligomis buvo 37 proc. mažesnis, nei urbanizuotose vietovėse [15-18].

J. Barton ir M. Rogerson pateikia statistiškai reikšmingu ịrodymų, kad buvimas gryname ore natūralioje aplinkoje ir kartu atliekama fizinè veikla gerina fizinę ir psichoemocinę žmogaus sveikatą. Bent kartą per savaitę gryname ore fizine veikla užsiimančių asmenų psichikos sveikata dvigubai geresnè, lyginant su tais, kurie tokios veiklos nevykdo. Pastebeta, kad sistemingai atliekant ịvairius fizinei sveikatai gerinti skirtus pratimus lauke, pagerėja žmonių gebejjimas dorotis su kasdienėmis problemomis, gerẻja jų psichoemocinè būklè [19]. Natūralių gamtinių veiksnių taikymas reabilitacijoje pagerina ir paspartina sveikimo procesus, padeda darbingo amžiaus žmonèms greičiau grịžti ị profesinę veiklą [20].

Austrijoje D. Huber ir kt., atlikę tyrimą, nustatè, kad natūraliais gamtiniais veiksniais gydant fizinę žmogaus sveikatą, teigiamų rezultatų galima pasiekti ir psichoemociniame lygmenyje. Tyrime dalyvavo 80 pacientų, kenčiančių nuo lètinio apatinès nugaros dalies skausmo, kurio gydymui iprastiniai medikamentai nebuvo veiksmingi. Tiriamieji buvo stebimi 120 dienų, o medicininiai tyrimai, siekiant nustatyti procedūrų veiksmingumą, buvo atliekami: pradëjus tyrimą, po 8 dienų (tiek laiko tiriamieji buvo apgyvendinti viešbutyje $1015 \mathrm{~m}$ virš jūros lygio) ir po 120 dienų (baigiantis tyrimo laikotarpiui). Tiriamieji suskirstyti i 3 grupes, iš kurių viena - kontrolinè. İ šią grupę patekę asmenys neužsiėmè jokia tyrime apibūdinta veikla, gyveno ịprastinị gyvenimą namuose. Vienos grupès tiriamieji vaikščiojo kalnuose 7 dienas per savaitę, po 5 valandas per dieną. Kitos - papildomai maudèsi natūraliose kalnų terminèse voniose, kuriose vandens temperatūra siekè $37^{\circ} \mathrm{C}$, po 20 minučiu 5 kartus per savaitę. Funkcinis nugaros paslankumas buvo vertinamas dviem judesių amplitudès bei nugaros lankstumo ir stabilumo matavimo skalemis (angl. Back Performance Scale, the Spine-Check Score MediMouse ${ }^{\circledR}$ ), kurios padejo vertinti gebejjimą sukti liemenį ir skausmą judesių metu. Psichoemocinè tiriamujų būklè vertinta naudojant sutrumpintą sveikatos apklausos klausimyno formą SF-36 (angl. Short form 36 medical outcomes study questionnaire). Viso tyrimo metu buvo rašomas skausmo dienoraštis, padedantis geriau suprasti skausmo kitimą tyrimo metu. Po tyrimo padarytos išvados, kad ilgalaikis skausmas ne tik neigiamai veikia sergančiojo kasdienybę, bet sukelia depresiją bei psichologinị nuovargi, kurie tyrimo metu respondentams sumažejo. Tai siejama su buvimu gryname ore: kvapais, žaluma, ivairiais lauke atliekamais pratimais. Po gydymo padidejo tiriamujų nugaros paslankumas, sumažejo skausmas judesių metu. Ypač gerų rezultatų pastebèta grupeje, turèjusioje galimybę maudytis terminiuose vandenyse. Tyrimas patvirtino, kad fizinè sveikata neatsiejama nuo psichoemocinès žmogaus sveikatos [21].

Balneoterapijos poveikis žmogaus psichikos ir fizinei sveikatai. Balneoterapija (gydymas mineraliniu vandeniu) nuo seno daugelyje pasaulio šalių taikomas gydymo metodas [22]. Iki šiol šiuolaikiniuose SPA centruose bei reabilitacijos įstaigose atliekamos procedūros, naudojant mineralinio vandens vonias bei baseinus [23]. Teigiama, kad tokios procedūros metu biologiškai aktyvios organinès ir neorganinès mineralinès medžiagos absorbuojasi per odą ir pasiekia reikiamus organizmo taškus, kartu mažindamos ir uždegiminių mediatorių (TNF- $\alpha$, IL-1 $\beta$, IL-6) skaičių tose vietose. Yra duomenų, kad balneoterapijos metu tokių biologinių žymenų skaičius labiausiai sumažeja sergantiesiems reumatoidiniu artritu. Procedūra išorinè, pradedama esant $38-42{ }^{\circ} \mathrm{C}$ vandens temperatūrai, kuri iš lèto mažèja procedūros mineralinèje vonioje metu [24].

Balneoterapija ypač efektyvi gydant lètines neurologines, reumatologines bei dermatologines ligas [24,25]. Sumažèja raumenų ir sąnarių skausmas, depresijos požymiai, pagerẻja gyvenimo kokybė, lyginant su laikotarpiu iki procedūrų taikymo [26].

Aprašytas teigiamas balneoterapijos streso mažinimo ir emocijų valdymo poveikis [24]. Toda atlikto tyrimo metu nustatyta, kad procedūros su mineraliniu vandeniu mažina streso hormono - kortizolio kieki organizme, padeda palaikyti pastovią neurotransmiterio serotonino pusiausvyrą, lemiančią mažesnius nuotaikos bei emocijų pokyčius, veikiant stresui. Balneoterapija mažina simpatinès nervų sistemos sujaudinimą, lemiantị gebejjimą nusiraminti. Taikant šią priemonę, gerẻja žmogaus psichikos sveikata [27]. O. Dubois ir kt. atlikto tyrimo metu, kuriame dalyvavo 237 respondentai, balneoterapijos taikymo poveikis buvo lyginamas su paroksetino (vaistas gydyti nerimą bei depresiją) poveikiu, gydant nerimo sutrikimą su pykčio protrūkiais. Respondentai buvo suskirstyti ị dvi grupes. Vienoje tiriamieji buvo gydyti paroksetinu, kitoje - balneoterapija. Tyrimas truko 8 savaites. Palyginti su gydymu parokestinu, tyrimo rezultatai parodè teigiamą ilgalaikị balneo- 
terapijos poveiki, valdant susierzinimą ir pykti [28-30].

Lietuvoje, Klaipèdos jūrininkų ligonineje atliktas tyrimas taip pat ịrodè balneoterapijos naudą streso mažinimui. Tyrime dalyvavo 180 25-64 metų jūreivių, dirbančių laivuose daugiau nei 5 metus. Jūreiviai patyrè nuovargị ir stresą, siekiantį 2 balus pagal vaizdinès analogijos skalę. Tiriamieji skundèsi raumenų-skeleto, gastrointestinalinès, urologinès sistemų problemomis. Visų prašyta tyrimo metu visiškai nekeisti kasdienès rutinos ir dirbti, kaip ịprasta. Balneoterapijai naudotas $34,6{ }^{\circ} \mathrm{C} \mathrm{Na}-\mathrm{Cl}-\mathrm{Ca}-\mathrm{Mg}-\mathrm{SO} 4$ mineralizuotas vanduo, kurio $\mathrm{pH}$ siekè 6,07. Procedūros buvo taikomos 2 savaites po 5 kartus per savaitę, po 15 minučių vieno seanso metu. Po šio laikotarpio įvertinus pacientų streso lygị, buvo stebimi akivaizdūs pokyčiai, įrodantys balneoterapijos naudą streso mažinimui, nes nuotaikos pagerẻjimas, juntamo nuovargio sumažejimas bei gebejjimas valdyti stresines situacijas kito statistiškai reikšmingai. Tyrimo metu neišvengta ir šalutinių reakcijų, tačiau jos buvo nesunkios, tokios kaip odos paraudimas ar bėrimas, psoriazès paūmèjimas, dèl kurių tyrimas nenutrauktas [31].

Dar vienas šioje ligoninèje atliktas panašaus pobūdžio tyrimas įrode palankią balneoterapijos įtaką streso mažinimui. Tyrime dalyvavo 250 atsitiktinai įtrauktų asmenų, kurie buvo suskirstyti i 5 grupes po 50 žmonių kiekvienoje: 3 grupès tirtos naudojant skirtingos mineralizacijos vandens vonias: $20,40,60 \mathrm{~g} / \mathrm{l}, 1$ grupe - su natūralaus vandens voniomis ir 1 kontroline grupè. Tyrimas truko 2 savaites, procedūros buvo taikomos 5 kartus per savaitę, o tiriamųų prašyta nekeisti ịprastinès kasdienès rutinos. Prieš tyrimą visiems dalyviams atlikti bendrieji kraujo ir šlapimo tyrimai. Po tyrimo stebėtas ne tik psichikos sveikatos pagerèjimas. Akivaizdžiai pakito ir kraujo tyrimų rezultatai: po terapijos su $20 \mathrm{~g} / \mathrm{l} \mathrm{mi-}$ neralizacijos vandeniu eritrocitų skaičius tiriamujų kraujyje sumažèjo, o po terapijos su $40 \mathrm{~g} / 1$ mineralizacijos vandeniu eritrocitų skaičius kraujyje padidejo. Ilgiausias liekamasis efektas (3 mènesius po procedūrų) buvo vandens vonių terapijos, kuriose vandens mineralizacija sieke $40 \mathrm{~g} / \mathrm{l}$. Nuovargis labiausiai sumažèjo tiriamujų, kuriems buvo taikyta $20 \mathrm{~g} / \mathrm{l}$ mineralizuoto vandens terapija. Tik 9 proc. tiriamuju bendroji sveikatos būklè buvo geresne prieš tyrimą, nei po jo [32]. Dažniau balneoterapija skiriama pacientams, kenčiantiems skausmą. Tyrimais ịrodyta, kad balneoterapija keletui mènesių sumažina lètinị apatinès nugaros dalies ar kaklo skausmą. Kartu padidejja sergančiujų judrumas, gebejjimas judèti, pagerèja gyvenimo kokybė $[33,34]$.

Natūralių gamtinių veiksnių poveikis psichofiziologiniam atsigavimui. S. Corazon ir kt., apibendrinę per aštuonerius metus moksliniuose leidiniuose įvairių autorių paskelbtų gamtinių veiksnių poveikio žmogui tyrimų rezultatus, prièjo prie išvados, kad asmenims, kenčiantiems nuo ilgalaikio streso, pervargimo bei depresijos, neretai sukeliančios ir fizinius susirgimus, gydymo natūraliais gamtiniais veiksniais metu pavykdavo pasiekti ryškaus pagerejjimo ar netgi visiško psichofiziologinio atsigavimo. Gerejo psichikos būklè, imuninès, širdies ir kraujagyslių sistemos veikla, todèl tiriamieji, patyrę ši fizinị ir psichikos komfortą, grižo i ịprastinį gyvenimą [35]. Manoma, kad didelès reikšmès tokiam atsigavimui turi žmogaus jutimų sistema, t. y., ką jis jaučia, kaip suvokia aplinką [36].

G. Cerwén su bendraautoriais vertino natūralių aplinkos garsų (tylos, paukščių čiulbèjimo, upelių čiurlenimo) poveikị asmens sveikatai. Nustatytas teigiamas poveikis, padejjęs tiriamiesiems nusiraminti, lengviau spręsti kasdienes problemas. Tokio pagerejjimo pasiekti padeda natūrali, tačiau kiekvieno žmogaus skirtinga, genetiškai nulemta klausa. Vieni jautresni įvairiems aplinkos garsams, kiti mažiau reaguoja ị garsinę aplinką [37, 38].

H. Jo su bendraautoriais atliktoje studijoje, kurioje dalyvavo 29 vieno Japonijos universiteto studentès, buvo ivertintas psichofiziologinis atsigavimas gamtos sąlygomis. Studentèms 1 minutę per ausines buvo leidžiami ịvairūs miško garsai, siekiantys 48,6 dB. Gautieji rezultatai parodè, kad tyrimo metu sumažèjo tiriamuju jautrumas, nes buvo sumažejęs simpatinės nervų sistemos aktyvumas, pavyko atsipalaiduoti, sulètejo širdies ritmas, tiriamosios buvo geresnès nuotaikos, pasijuto pailsejjusios. Gebejjimas nusiraminti, suvaldyti mintis bei emocijas gamtos sąlygomis aiškinamas ne tik simpatinès nervų sistemos aktyvumo, bet ir oksihemoglobino koncentracijos sumažejimu dešinèje prefrontalinèje smegenų žievės dalyje $[39,40]$.

M. Repke ir kt. teigimu, natūralūs gamtiniai veiksniai fizinę ir psichikos sveikatą veikia panašiai. Stebint, būnant natūralioje gamtoje, sergantiesiems sumažèja skausmas, padidèja gebejjimas adekvačiai ị jị reaguoti ir valdyti skausmo metu užvaldžiusias neigiamas emocijas, gereja pažintinès funkcijos. Visa tai lemia greitesnę asmens integraciją ị visuomenę, sklandesnius socialinius ryšius po buvusio psichofiziologinio išsekimo [40, 41].

Žmogaus sveikata neatsiejama nuo klimato ir greitos jo kaitos. Klimatas turi itakos maisto ir geriamojo vandens kokybei, nuo kurios priklauso ir sveikata. Tyrimų metu nustatyta, kad greiti ir ekstremalūs gamtos pokyčiai gali sukelti depresijos, streso bei pykčio priepuolius. Ištirta, kad labiausiai paveikiamos grupès yra: vietiniai gyventojai, vaikai, senoliai, moterys bei žemo socialinio statuso asmenys [42]. Nors tokia teorija nèra iki galo ištirta ir suprasta, tačiau sveikatos problemų, nulemtų klimato kaitos, vis daugeja ir, spejjama, daugès. Netgi tokie, jau beveik ịprastiniais tapę, ịvykiai, kaip uraganai, potvyniai paveikia fizinę (kūno sužalojimai) ir psichikos (stresas, išgąstis) sveikatą. Dèl šių priežasčių 
svarbu brandinti suvokimą, kad naudodami gamtos išteklius gerinti savo sveikatą ir buitį, turime išsaugoti natūralų klimatą [42-44].

\section{Išvados}

1. Iprastinis kasdienis buvimas gamtoje palankiai veikia žmogaus psichikos sveikatą, mažina polinkị i depresiją.

2. Mineralinio vandens procedūros teigiamai veikia psichikos ir fizinę žmogaus sveikatą, mažina skausmą, gerina nuotaiką bei gyvenimo kokybę.

\section{Literatūra}

1. Slavich GM. Life Stress and Health: A review of conceptual issues and recent findings. Teach Psychol 2016;43(4):346-355.

https://doi.org/10.1177/0098628316662768

2. Mariotti A. The effects of chronic stress on health: new insights into the molecular mechanisms of brain-body communication. Future Sci OA 2015;1(3):FSO23.

https://doi.org/10.4155/fso.15.21

3. Yaribeygi H, Panahi Y, Sahraei H, Johnston TP, Sahebkar A. The impact of stress on body function: a review. EXCLI J 2017;16:1057-1072.

4. England BR, Mikuls TR. Epidemiology of, risk factors for, and possible causes of rheumatoid arthritis. UpToDate 2019.

5. Annual European congress of rheumatology EULAR 2018. Rheumatic Diseases Factsheet 2018.6. Jain VK, Singh Negi V. Inflammatory rheumatic diseases in the elderly. Department Clinical Immunology 2016;11(4):207-215.

https://doi.org/10.4103/0973-3698.192684

7. Feuchten berger M, Nigg AP, Kraus MR, Schäfer A. Rate of proven rheumatic diseases in a large collective of referrals to an outpatient rheumatology clinic under routine conditions. Clin Med Insights Arthritis Musculoskelet Disord 2016;9:181-187. https://doi.org/10.4137/CMAMD.S40361

8. McDougall C, Hurd K, Barnabe C. Systematic review of rheumatic disease epidemiology in the indigenous populations of Canada, the United States, Australia, and New Zealand. Semin Arthritis Rheum 2017;46(5):675-686.

https://doi.org/10.1016/j.semarthrit.2016.10.010

9. Radner H. Multimorbidity in rheumatic conditions. Wien Klin Wochenschr 2016;128(21-22):786-790. https://doi.org/10.1007/s00508-016-1090-x

10. Amoako AO, Pujalte GG. Osteoarthritis in young, active, and athletic individuals. Clin Med Insights Arthritis Musculoskelet Disord 2014;7:27-32.

https://doi.org/10.4137/CMAMD.S14386

11. Euesden J, Matcham F, Hotopf M, et al. The relationship between mental health, disease severity, and genetic risk for depression in early rheumatoid arthritis. Psychosom Med 2017;79(6):638-645.

https://doi.org/10.1097/PSY.0000000000000462

12. Becker WC, Dorflinger L, Edmond SN, Islam L, Heapy
AA, Fraenkel L. Barriers and facilitators to use of non-pharmacological treatments in chronic pain. BMC Fam Pract 2017;18(1):41.

https://doi.org/10.1186/s12875-017-0608-2

13. Woźniak-Holecka J, Romaniuk P, Holecki T, FrączkiewiczWronka A, Jaruga S. Health promotion development in the spa treatment. Perspectives for the European countries learned from Poland's experiences. Front Pharmacol 2017;8:29.

https://doi.org/10.3389/fphar.2017.00029

14. Logan AC, Katzman MA, Balanzá-Martínez V. Natural environments, ancestral diets, and microbial ecology: is there a modern "paleo-deficit disorder"? Part I. J Physiol Anthropol 2015;34:1. https://doi.org/10.1186/s40101-015-0041-y

15. Keniger LE, Gaston KJ, Irvine KN, Fuller RA. What are the benefits of interacting with nature? Int J Environ Res Public Health 2013;10(3):913-935.

https://doi.org/10.3390/ijerph10030913

16. Barton J, Pretty J. What is the best dose of nature and green exercise for improving mental health? A multi-study analysis. Environmental Science Technology 2010;44(10):3947-3955. https://doi.org/10.1021/es903183r

17. Aerts R, Honnay O, Van Nieuwenhuyse A. Biodiversity and human health: mechanisms and evidence of the positive health effects of diversity in nature and green spaces. British Medical Bulletin 2018;127(1): 5-22.

https://doi.org/10.1093/bmb/ldy021

18. Bhatnagar A. Environmental determinants of cardiovascular disease. Circulation Research 2017;121:162-180. https://doi.org/10.1161/CIRCRESAHA.117.306458

19. Barton J, Rogerson M. The importance of green space for mental health. B J Psych Int 2017;14(4):79-81.

https://doi.org/10.1192/S2056474000002051

20. Grahn P, Pálsdóttir AM, Ottosson J, Jonsdottir IH. Longer nature-based rehabilitation may contribute to a faster return to work in patients with reactions to severe stress and/or depression. Int J Environ Res Public Health 2017;14(11):1310.

https://doi.org/10.3390/ijerph14111310

21. Huber D, Grafetstätter C, Proßegger J, Pichler C, Wöll E, Fischer M, Dürl M, Geiersperger K, Höcketstaller M, et al. Green exercise and mg-ca-SO4 thermal balneotherapy for the treatment of non-specific chronic low back pain: a randomized controlled clinical trial. BMC Musculoskelet Disord 2019;221:20.

https://doi.org/10.1186/s12891-019-2582-4

22. Gianfaldoni S, Tchernev G, Wollina U, et al. History of the baths and thermal medicine. Open Access Maced J Med Sci 2017;5(4):566-568.

https://doi.org/10.3889/oamjms.2017.126

23. Valeriani F, Margarucci LM, Romano Spica V. Recreational use of spa thermal waters: criticisms and perspectives for innovative treatments. Int J Environ Res Public Health 2018;15(12):2675. https://doi.org/10.3390/ijerph15122675 
24. Gálvez I, Torres-Piles S, Ortega-Rincón E. Balneotherapy, immune system, and stress response: a hormetic strategy? Int J Mol Sci 2018; 19(6):1687.

https://doi.org/10.3390/ijms19061687

25. Karagülle M, Karagülle MZ. Effectiveness of balneotherapy and spa therapy for the treatment of chronic low back pain: a review on latest evidence. Clin Rheumatol 2015;34(2):207-14. https://doi.org/10.1007/s10067-014-2845-2

26. Blain H, Bernard PL, Canovas G, Raffort N, Desfour H, Soriteau L, Noguès M, Camuzat T, Mercier J, Dupeyron A, Quéré I, Laffont I et. al. Combining balneotherapy and health promotion to promote active and healthy ageing: the balaruc-MACVIALR® approach. Aging Clin Exp Res 2016; 28(6):1061-1065. https://doi.org/10.1007/s40520-016-0596-4

27. Bongiorno P. A cold splash-hydrotherapy for depression and anxiety. Can hot and cold water make a difference in your mood? Psychology today. 2014.

28. Sarris J, de Manincor M, Hargraves F, Tsonis J. Harnessing the four elements for mental health. Front Psychiatry 2019;10:256. https://doi.org/10.3389/fpsyt.2019.00256

29. Drug information database. 2019. https:/www.drugs.com/ paroxetine.html

30. Dubois O, Salamon R, Germain C, Poirier MF, Vaugeois C, Banwarth $\mathrm{B}$, et al. Balneotherapy versus paroxetine in the treatment of generalized anxiety disorder. Complement Ther Med 2010;18(1):1-7.

https://doi.org/10.1016/j.ctim.2009.11.003

31. Rapolienė L, Razbadauskas A, Sąlyga J, Martinkėnas A. Stress and fatigue management using balneotherapy in a short-time randomized controlled trial. Evid Based ComplementAlternat Med 2016;2016:9631684.

https://doi.org/10.1155/2016/9631684

32. Rapolienè L, Gedrimė L, Razbadauskas A, Skarbalienė A. Geothermal water for health state improvement: randomised controlled study. Balneo Research Journal 2019;10(2):153-166. https://doi.org/10.12680/balneo.2019.255

33. Matsumoto S. Evaluation of the role of balneotherapy in rehabilitation medicine. J Nippon Med Sch 2018;85(4):196-203. https://doi.org/10.1272/jnms.JNMS.2018_85-30

34. Koyuncu E, Ökmen BM, Özkuk K, Taşoğlu Ö, Özgirgin N. The effectiveness of balneotherapy in chronic neck pain. Clin Rheumatol 2016;35(10):2549-55. https://doi.org/10.1007/s10067-016-3199-8

35. Corazon SS, Sidenius U, Poulsen DV, Gramkow MC, Stigsdotter UK. Psycho-physiological stress recovery in outdoor naturebased interventions: a systematic review of the past eight years of research. Int J Environ Res Public Health 2019;16(10):1711. https://doi.org/10.3390/ijerph16101711

36. Franco LS, Shanahan DF, Fuller RA. A review of the benefits of nature experiences: more than meets the eye. Int J Environ Res Public Health 2017;14(8):864.

https://doi.org/10.3390/ijerph14080864
37. Cerwén G, Pedersen E, Pálsdóttir AM. The role of soundscape in nature-based rehabilitation: a patient perspective. Int J Environ Res Public Health 2016;13(12):1229. https://doi.org/10.3390/ijerph13121229

38. Alvarsson JJ, Wiens S, Nilsson ME. Stress recovery during exposure to nature sound and environmental noise. Int J Environ Res Public Health 2010;7(3):1036-1046.

https://doi.org/10.3390/ijerph7031036

39. Jo H, Song C, Ikei H, Enomoto S, Kobayashi H, Miyazaki Y. Physiological and psychological effects of forest and urban sounds using high-resolution sound sources. Int J Environ Res Public Health 2019;16(15):2649.

https://doi.org/10.3390/ijerph16152649

40. Repke MA, Berry MS, Conway LG 3rd, Metcalf A, Hensen $\mathrm{RM}$, Phelan C. How does nature exposure make people healthier? Evidence for the role of impulsivity and expanded space perception. PLoS One 2018;13(8):e0202246.

https://doi.org/10.1371/journal.pone.0202246

41. Berto R. The role of nature in coping with psycho-physiological stress: a literature review on restorativeness. Behav Sci (Basel) 2014;4(4):394-409.

https://doi.org/10.3390/bs4040394

42. Hayes K, Blashki G, Wiseman J, Burke S, Reifels L. Climate change and mental health: risks, impacts and priority actions. Int J Ment Health Syst 2018;12:28.

https://doi.org/10.1186/s13033-018-0210-6

43. Ebi KL, Hess JJ, Watkiss P. Health risks and costs of climate variability and change. Injury Prevention and Environmental Health 2017.

https://doi.org/10.1596/978-1-4648-0522-6_ch8

44. Grasso M, Manera M, Chiabai A, Markandya A. The health effects of climate change: a survey of recent quantitative research. Int J Environ Res Public Health 2012;9(5):1523-1547. https://doi.org/10.3390/ijerph9051523

\section{NATURAL ENVIRONMENT IMPACT ON PHYSICAL AND MENTAL HEALTH OF WORKING: AGE POPULATION U. Žilinskaitè, L. Varžaitytė}

Keywords: natural environment, balneotherapy, physical and mental health, stress and nature, climate and health.

Summary

Both physical and mental health have very strong connection to surrounding environment. Many natural resources are used to treat different diseases. Even simple being and exercising in nature have very good results on our mental and pshysical health. It's like a circle - good mental health affects good physical health and vice versa. In this study we examined science literature about human and environment connection. All the results show that human can't be without nature ant nature can't be without human. Total body wealth can be reached by treating it with natural resources.

Correspondence to: ugnzil@gmail.com

Gauta 2020-03-18 